tinued, and I ordered s small portion of the following ointment to be rubbed in over the seat of pain, night and marning.

R. Unguenti hydrargyri fortioris, unguenti camphoræ, āā ̧̧ss; extracti belladonne gr. iv. Fiat unguentum.

June 6th. (Her sister was married on this day.) She had a violent hysterical attack, which gare way to the usual remedies, quiet and opium. Pulse 96 ; rather better in character, but still feeble. The ointment was ordered to be continued.

June 9th. Pain diminished; she was able to sit in a chair comfortably for the first time.

June 13th. She had a slight hysterical attack for half an hour, which subsided without medical interference.

June 20th. The abdominal pain had materially abated, indeed was not perceptible, except on pressure over the part. Her appetite had been failing for the last two or three days, and she complained of a feeling of heat at the stomach. Continue the ointment.

R Potassa bicarb. $3 \mathrm{ij}$; acidi citrici 3 iss; acidi hydrocyanici diluti $m \times$ ij ; aquæe destillatæ ad $\bar{\jmath}^{\mathrm{vj}}$. Fiat mist. Capiat zj ter quotidie.

June 30th. She was now entirely free from pain; her general health improved; appetite good, and she had no bad symptom of any kind. She had no return of hysteria since the 13th.

REMarkg. The above case presents no features opposed to the views which I advanced in my last paper concerning the etiology of hysteria, that a peculiar condition of the nervous system is a predisposing cause, and that the ovarian lesion is very frequently an exciting cause. This patient had never observed any irregularity in the orariouterine system, and she.had not been habitually liable to hysteria. She had once had an attack of this nature, and it is not unreasonable to suppose that, synchronous with this, at the age of puberty, or soon after, there may have been some slight disorder of the generative system, which had escaped her notice. On the present occasion, we find her suffering from both ailments, and the one disappearing simultaneously with the other. The immediate cause of the ovarian inflammation remains a question. It was not improbably owing either directly to the accident before mentioned, or indirectly to the enteric affection in the neighbourhood. Though the ovarian lesion had probably existed for several weeks, hysterical symptoms did not take place until the marriage of her sister, which, occasioning her considerable excitement, disturbed the whole nervous system. As regards the treatment of such cases, I have found leeches, and the milder preparations of mercury, to be among the most efficacious, and the use of the latter is seldom required to be pushed so far as to affect the gums. In this case, leeches were not applied, as there had been a sufficient drain upon the circulating system at the time of the confinement. The sanguineous and nervous systems were well balanced but if there was any tendency to an abnormal state, it would be to the hyperæmic condition.

\section{CASES OF LITHOTONY.}

By Wrumam Thoras Bend, Esq., Great Grimsby.

Case I. Lithotomy: Rapid Recovery. Charles Pearson, aged 5 years, a widow's son, of fair complexion, light hair blue eyes, and healthy appearance, came under my care in November 1855. He had suffered for twelve months from symptoms of stone, varying in intensity, with occasional difficulty in passing urine, and roiding it more frequently than natural, with pain at the end of the penis, which caused him to pull the prepuce. When passing his urine, he would have a desire to go to stool at the same time, producing prolapsus ani. During the last two months, his symptoms had kept increasing; he could not hold his water for long at a time. His urine was clear, and he passed no blood. His general health was very good. A sound was introduced into the bladder, but I could not de- tect stone. He licked about much; and the bladder would not tolerate any water to be injected. $\Delta$ few daje afterwards, under chloroform, I sounded him a second times, and readily felt one. As his mother was not in a good stato of health, the operation was postponed for a time. In this interval, he took carbonate of soda and tincture of henbane, with mucilage; and kept his bowels open with castor oil.

January 13th, 1856. Under chloroform, I performed the lateral operation of lithotoiny. There was no bleeding. The calculus was of about the size of a bean, long and soft, and would scarcely bear the forceps. Afterwards an opiate was given. During the night, he passed his urine by the urethra, and freely by the wound. At night, another opiate was given.

Jan. 14th. He slept well during the night; urine continued to pass as above. There was slight fever. I ordered a saline draught every four hours; and a powder, with calonel and Dover's powder, at bedtime.

Jan. 15th. Doing very well.

Jan. 16th. The bowels were not moved. I ordered a dose of castor oil. Urine passed freely by the urethra, and very little through the wound. The saline was continued.

Jan. 17th. Going on very well. I ordered him a better diet, and to leave off the saline.

In three wecks time he was perfectly cured.

CASE II. Lithotomy. James Lingard, aged 63 years, labourer, of short stature, much care-worn, came under my care in July 1855, with stune in the bladder. He had always enjoyed good health up to three years ago.

Uistory of Disease. Thirty years ago, he passed a quantity of lithic acid sand; and three years ago he passed two small calculi without much difficulty; and ever since this had been getting worse, and for the last year had been incapacitated from work.

The symptoms were those usual to stone in the bladder. There was a considerable deposit of mucus in the urine upon standing. I sounded him, and found a stone of large size, measuring $14^{\circ}$ of Ferguson's lithotrite. There was considerable enlargement of the prostate gland. He was anxious to have the stone crushed; but, taking into consideration the irritability of the patient, the hardness of the stone, and the enlargement of the prostate gland, with an assurance that he would not keep in bed for any length of time, I detcrmined to perform the lateral operation of lithotomy.

July 2nd. Under chloroform, I performed lithotomy. The operation lasted $t w 0$ and a half minutes. There was rather free hæmorrhage at the time from the transverse artery of the perinæum and the reins of the prostate. To arrest this, I plugged the wound with sponge, and put an elastic catheter into the bladder; brought the knees together, and gave an opiate.

The after treatment consisted in low diet for a few days, with salines; then a good generous diet, with porter, and tobacco to smoke ad libituin. He made a good recovery, and walked to my surgery, a distance of a hundred yards, three days within the month after the operation, although the wound was not quite healed. In a few days after this, he went home, a distance of eight miles; and I lost sight of him for a time. Some time after the operation, a small fistulous opening remained in the perinæum, but he refused to have anything done for its relief.

The calculus was flat, and of the circumference of a full sized walnut, composed of distinct laminæ, and very hard.

\section{CASE OF PLURAL BIRTH.}

By R. Coker N. Davies, Esq., Rye, Sussex.

Or the morning of December 14th, 1855, I was summoned to the union house, to attend - M., aged 19 years, single. On arrival, I found her to be in labour. The membranes had broken, and a head presented. The child was soon born; and after waiting a little time, and making 